\title{
Concerning Multinational Staff Efficiency and Future NATO Operations
}

\author{
Walter E. Kretchik*
}

Following the end of the Cold War in the early 1990s, North Atlantic Treaty Organization (NATO) military forces engaged in a series of out-of-area missions involving peace operations. The operational staffs involved in controlling these operations entered an often bewildering world of United Nations reports, incorporating Alliance and non-Alliance partners into their own military procedures, and working alongside numerous civilian agencies representing non-government and private volunteer organizations. As the NATO Implementation Force (IFOR) discovered in 1996, success for ad hoc multinational headquarters in the post-Cold War era often came down to the personalities of individual commanders and staff members, but not necessarily overall staff efficiency. ${ }^{1}$

While particular commanders and staff members can make a difference during a military operation, NATO staff officers continue to bear the burden of controlling the day-to-day activities within the area of operation that lead to mission success or failure. Given the complexity of today's peace operations, an efficient and effective NATO operational staff in the field seems vital for mission accomplishment. Yet, without a cohesive staff to issue orders, gather and submit reports, sort through crises, and monitor numerous activities, a commander often must divert personal time to mundane tasks that distract from the broader operational perspective. Staff efficiency becomes essential for freeing the commander to focus on mission accomplishment rather than headquarters bureaucracy.

While developing an efficient staff is an admirable goal, attempting to build staff cohesion during a crisis can be frustrating. Much of this aggravation originates with the staff members themselves, many of whom often have been added to the headquarters at the last minute as replacements or necessary experts. Such individuals often arrive in theater lacking the necessary decision-making skills, suffer from language or terminology differences, or have little - if any-familiarity with often complex reporting procedures. Given the daily pace of an ongoing operation, making up deficiencies in staff skills is difficult at best.

Creating an efficient staff means forming the headquarters in advance and training the members to a common standard. While this is not always possible due to the timesensitive nature of international crises, there are instances where staff cohesion can be

* Walter E. Kretchik is an Assistant Professor of U.S. military history and foreign relations at Western Illinois University, Macomb, Illinois. A retired army officer with over ten years experience in Europe, Professor Kretchik also served as the U.S. Army's Command Historian in Bosnia in 1996. He has published articles on multinational staff effectiveness in several academic journals.

1 Larry Wentz, contributing ed., Lessons From Bosnia: The IFOR Experience (Washington, D.C.: Department of Defense Command and Control Research Program, 1998), 35. 
improved before the beginning of a mission. Such was the case of the United Nations Mission in Haiti (UNMIH) in 1995-96. Formed prior to mission assumption from a United States military joint task force, UNMIH staff members received extensive preparation from a multinational training team prior to mission handover. Once training ended, the United Nations (UN) mission commander, U.S. Army Major General Joseph Kinzer, had complete confidence in his staff members to handle any situation as it arose. ${ }^{2}$

Given the success of UNMIH in attaining UN goals in supporting the elected government of Haiti between 1995 and 1996, this paper suggests that NATO leaders should examine the UNMIH case as one model for successfully transforming an ad hoc group of multinational individuals into a cohesive staff. In doing so, this article addresses the following questions: Why should NATO leaders try to improve operational staff effectiveness? What steps can be taken in pursuit of this improvement?

\section{Preparing the Trainers}

Conceived of in late 1994 by United States Army General Gordon Sullivan, a multinational training team began to form around the service's Battle Command Training Program, or BCTP, in October. BCTP, an army training organization formed in the 1980s to train senior-level staffs in decision-making skills, was to be augmented by international peacekeeping experts. After negotiations over the nature and composition of the training team between the UN, the Joint Chiefs of Staff, and other agencies concluded in late January 1995, the UN Security Council released SCR 975, authorizing the transition of Haitian security responsibility from a U.S. multinational force to UNMIH no later than 31 March 1995, and preparation of the headquarters began. ${ }^{3}$

For several months, members of the UN, the Joint Chiefs of Staff, United States Atlantic Command, and the U.S. Army had worked hard to find the right personnel with both the credibility and knowledge to train a multinational staff for a peace operation. With the necessary permissions in place, the UNMIH staff trainers first arrived at Fort Leavenworth, Kansas, for a certification phase in late February 1996. In addition to BCTP training officers, this group included Brigadier General Abdul Ghani from the UN Department of Peacekeeping Operations, several military officers with peacekeeping experience from Canada, Austria, and the U.S., and civilian experts from a variety of $\mathrm{UN}$ agencies and academic institutions. ${ }^{4}$

While the various trainers possessed a wealth of knowledge in UN peacekeeping operations, it was crucial that everyone understand the mission. Above all, the team was to prepare the UNMIH staff to support UN objectives and the government of Haiti in democratizing the nation. To meet those goals, it was important that the trainers comprehend how the UN was currently organized and operated, and the training team

2 Interview with Lieutenant General Joseph W. Kinzer by author, Fort Sam Houston, Texas, 28 June 1998.

3 United Nations, UN Security Council Resolution 975, 30 January 1995.

4 Battle Command Training Program, "UNMIH training personnel roster," unpublished manuscript, undated. BCTP archives, Fort Leavenworth, Kansas. 
received an orientation in such matters. As far as assisting the Haitian government was concerned, knowledge of that country's culture was paramount. Dr. Bryant Freeman, a civilian expert on Haitian society, was brought in to offer his views on important areas of mission concern, including customs, the legal system, politics, and Haitian life.

Following a series of such briefings, the trainers participated in a U.S.-designed leadership exercise to demonstrate how seemingly disparate individuals can be assimilated quickly into decision-making groups. ${ }^{5}$ For two days, the BCTP training staff supervised members of the international community as they conducted instruction on UN support agency capabilities, followed by a seminar on decision-making methodology. 6

Throughout the process, the trainers underwent a series of exercises designed to reinforce their knowledge of decision-making methods. This element was undertaken for two reasons: to ensure that every trainer understood the lesson material that they would pass on to their students, and to guarantee instructor credibility with the students. Upon completion of these sessions, the BCTP mentors certified the training team as prepared to conduct UNMIH staff instruction.

\section{Training The UNMIH Staff}

Because the UNMIH staff had already deployed to Port-au-Prince in anticipation of accepting mission handover from the U.S. JTF 190 within thirty days, staff training was conducted on site. The training team arrived in Haiti on 4 March 1995, with the purpose of training the staff so that they would be capable of implementing SCR 940 and assisting the Haitian government with the establishment of democratic practices as required. In attendance were General John Shalikashvili, Chairman, Joint Chiefs of Staff; Major General George Fisher, Commander of Multinational Forces Haiti; and Major General Joseph W. Kinzer, UNMIH commander, with each speaking to the group about how the UNMIH staff was a key element for furthering democratic values in Haiti. In addition, retired Major General Clive Milner recalled his experiences as a former multinational force commander and the difficulties associated with commanding a multicultural force. ${ }^{7}$

Representatives from the UN Civilian Affairs Office explained the UN's structure, the command relationship between the UN and UNMIH, and procedures for how different UN agencies supported the UNMIH staff. Lectures included the nature of peacekeeping operations, information on the UN charter, the relationship of politicalinformational-military aspects of peacekeeping, the legal authority for the implementation of UNMIH, and civilian population perceptions of UN peacekeepers. ${ }^{8}$

5 Battle Command Training Program, "UNMIH Facilitator Training," unpublished manuscript, 27 February 1995; BCTP archives.

6 Interview with Lieutenant Colonel Daniel Ward by author, May 1995, Fort Leavenworth, Kansas.

7 Battle Command Training Program, "UNMIH Training Schedule," unpublished manuscript, 5 March 1995; BCTP archives.

8 BCTP, "UNMIH Training Schedule," 7. 
A second session began early on 6 March 1995, which covered nuances of Haitian religion, meal schedules and food consumption, personal relationships, gestures, languages, and custom taboos. ${ }^{9}$ The joint task force headquarters intelligence section then presented a two-hour briefing on the current social, military, economic, and political situation in Haiti. A Norwegian officer with UN peacekeeping experience offered a session on liaison work with host governments and negotiation techniques, stressing how difficult it was to mesh UN SCR requirements with host government political and economic desires. Following the lectures, UNMIH staff members organized into functional area syndicates, each specific to intelligence, operations, and logistical areas. Small-group mentors directed these groups in UN staff processes, including routine and emergency reporting procedures and headquarters coordination methods. ${ }^{10}$

The next morning, the syndicates reformed into mixed groups, which included at least one officer from each staff specialty. The training audience thus created several miniature headquarters, each group containing the requisite staff functions that the UNMIH staff had to perform. Each syndicate and designated mentor spent the day engaged in small group problem-solving exercises that encouraged individuals to agree on a common goal quickly, and then to work as a group to solve the problem. ${ }^{11}$ After the exercise, members conducted a "hot wash" where they each addressed how they had approached the problem and thus learned from each other.

On 8 March, the staff received information briefings on UN civil and military policies, including the Status of Mission Agreement, or SOMA, the key legal agreement between the UN and the Haitian government that established how peacekeepers would enforce UN resolutions. A legal officer discussed the UN Rules of Engagement (ROE), or the guidelines regulating UN troop behavior in accomplishing their tasks. After the briefing, the students participated in a series of U.S.-designed scenarios to test their ROE decision-making abilities.

Numerous trainers led seminars on how the UN coordinated activities with outside agencies, international organizations, and the government of Haiti, and on the use of internal development resources. A representative from the U.S. Agency for International Development presented a lecture on the role of newspapers, radios, and television broadcasts in conveying both public and military information to the Haitian people. The final briefings consisted of a series of presentations on decision-making proc-

9 Interview with Lieutenant Colonel Thomas Adams by author, 16 November 1995, Fort Leavenworth, Kansas. According to Adams, Freeman talked for two hours and covered Haitian geography, environmental concerns, the political climate and social strata, and Haitian history. He also lectured on Haitian views of morality, the nation's birth and death rates, the local attitudes regarding foreigners and natives, economics, and issues concerning everyday life in Haiti.

10 Battle Command Training Program, "Revised UNMIH Training Schedule," unpublished manuscript, 6 March 1995; BCTP archives.

11 BCTP, "Revised UNMIH Training Schedule." 
esses. One UNMIH staff officer later recalled that the training "was without a doubt the most intensive staff preparation that he had experienced in his military career.",

The final training consisted of a computer simulation decision exercise using the VICTOR computer program. The UNMIH staff established a headquarters replicating the one they would initiate with mission handover on 31 March 1995. For two days, under mentor supervision, staff officers conducted twenty-four hour operations with the VICTOR computer generating events such as reports of pilferage, riots, gunfire incidents, and distinguished visitor arrivals. ${ }^{13}$

In less than forty-eight hours, the UNMIH staff had established a routine and functioned at an acceptable level of efficiency. On 10 March 1995, they completed their four days of training. After watching the proceedings, Major General Baril declared that the UNMIH staff had "the appropriate means to assist the government of Haiti in implementing democratic reform." Several staff officers remarked that they had renewed confidence in themselves and, for the first time, there was a clear understanding of just what was expected of a multinational staff. ${ }^{14}$ Twenty-one days later, Kinzer assumed command of UNMIH and his staff commenced their duties.

In 1998, Kinzer recalled that the UNMIH staff performed its duties better than any UN organization to date, and attributed this cohesion to the advance training process that took place in 1995. When pressed about why he believed that to be true, the general remarked that UNMIH operated similarly to any high-level U.S. headquarters that he had served in. Briefings were well organized, and staff officer reports were concise. Daily crises were handled without undue disruption and, with his confidence in his staff assured, he was able to concentrate on his charter: to assist the government of Haiti in preparing for democratic national elections. ${ }^{15}$

Discussions with UNMIH staff officers revealed similar reports. Staff members, many of them veterans of past UN deployments, found the staff to be more efficient than any previous multinational entity that they had served with. ${ }^{16}$ Many officers commented that for the first time they understood precisely what they were doing and where they fit within "the big picture."17 For both Kinzer and his staff officers,

${ }^{12}$ Unidentified Canadian lieutenant colonel, "UNMIH After Action Report," unpublished manuscript, 18 March, 1995; BCTP archives.

13 A typical exercise day began with a thirty-minute shift-change briefing as one half of the staff handed over duties to the oncoming shift. The UNMIH commander then received a morning update briefing regarding significant activities in the past twelve hours, a schedule for the current day, and a list of critical events that were expected within the next few weeks. Adams interview.

14 Interview with Colonel William Fulton by Robert F. Baumann, Port-au-Prince, Haiti, January 1996.

15 Kinzer interview.

${ }^{16}$ Fulton interview.

17 Interview with Lieutenant Colonel George Steuber by author, Fort Leavenworth, Kansas, April 1998. Ward interview. Ward related comments received by various multinational officers, including written feedback concerning their training and the assessment of their duties during the operation. 
UNMIH was an organizational effectiveness success story.

\section{Looking Forward}

This article briefly examined how a U.S. initiative resulted in the training of a UN staff prior to deployment to improve efficiency. In doing so, it asked, Why should NATO leaders try to improve operational staff effectiveness, and what steps can be taken to achieve this goal?

In addressing the "why bother" query, NATO leaders must improve operational staff effectiveness for at least two reasons: deployments involving NATO-led multinational peacekeeping forces are likely to continue for the foreseeable future and because controlling peace operations is as complex a task for a staff as under wartime conditions. In contemporary operations ongoing in Bosnia and Kosovo, military leaders and their staffs must not only control forces, but also process information at phenomenal rates through a variety of inputs, make sense of developing situations and advise commanders, and work with and among diverse agencies. Making sense of it all requires a staff with a high degree of cognitive skill and a shared understanding of procedures. While such skills can be acquired on the job over time, this process can take several weeks before an individual or section is operating at peak performance. As seen with the UNMIH case, pre-training conducted by a NATO team of experts for a deploying headquarters can reduce the learning curve among the staff and build confidence quickly, thus increasing mission success probabilities and reducing bureaucratic confusion, particularly when the initial deployment commences.

In asking what can be done, the UNMIH case deserves our attention because it was the first attempt to train a UN multinational staff for peace operations prior to mission assumption. At a cost of about $\$ 550,000$ and four days of training, the UNMIH staff officers, representing officers from numerous countries and each with varying skill levels, were molded into an effective staff. ${ }^{18}$ Throughout $1995-96$, the staff successfully met UN and Haitian government objectives as they monitored ongoing operations and provided assistance with national elections, among other duties.

While not every deployment affords the same conditions for staff training that existed for $\mathrm{UNMIH}$, such as an organized handover from one headquarters to another, NATO leaders should identify scenarios where the use of a multinational mobile training team is suitable. Such a team does not have to be permanent but must include the best available experts in order to be legitimate. At a minimum, NATO should identify and maintain a list of military and civilian personnel with experience in multinational operations and staff procedures that can be brought together to train an ad hoc operational headquarters. With today's strategic circumstances that often require an operational multinational headquarters forming "on the fly," relatively inexpensive pretraining may mean the difference between mission success or failure.

${ }^{18}$ Costs per BCTP archives. 